Annals of Applied Biology, 147, 161-172.

doi:10.1111/j.1744-7348.2005.00023.x

\title{
A foliar disease model for use in wheat disease management decision support systems
}

\author{
By ERIC AUDSLEY ${ }^{1 *}$, ALICE MILNE ${ }^{1}$ and NEIL PAVELEY ${ }^{2}$ \\ ${ }^{1}$ Silsoe Research Institute, Wrest Park, Silsoe, Bedford. MK45 4HS, UK \\ ${ }^{2}$ ADAS High Mowthorpe, Duggleby, North Yorkshire, YO17 8BP, UK
}

\begin{abstract}
Summary
A model of winter wheat foliar disease is described, parameterised and tested for Septoria tritici (leaf blotch), Puccinia striiformis (yellow rust), Erysiphe graminis (powdery mildew) and Puccinia triticina (brown rust). The model estimates diseaseinduced green area loss, and can be coupled with a wheat canopy model, in order to estimate remaining light intercepting green tissue, and hence the capacity for resource capture. The model differs from those reported by other workers in three respects. Firstly, variables (such as weather, host resistance and inoculum pressure) which affect disease risk are integrated in their effect on disease progress. The agronomic and meteorological data called for are restricted to those commonly available to growers by their own observations and from meteorological service networks. Secondly, field observations during the growing season can be used both to correct current estimates of disease severity and modify parameters which determine predicted severity. Thirdly, pathogen growth and symptom expression are modeled to allow the effects of fungicides to be accounted for as protectant activity (reducing infections which occur postapplication) and eradicant activity (reducing growth of pre-symptomatic infections). The model was tested against data from a wide range of sites and varieties, and was shown to predict the expected level of disease sufficiently accurately to support fungicide treatment decisions.
\end{abstract}

Key Words: winter wheat, foliar diseases, weather, disease observations

Audsley, E., Milne, A.E. and Paveley, N. (2006) A foliar disease model for use in wheat disease management decision support systems. Annals of Applied Biology, 147, 161172.

\footnotetext{
* Corresponding Author E-mail: eric.audsley@bbsrc.ac.uk
} 


\section{Introduction}

For foliar diseases of wheat, the extent and duration of disease-induced loss of green lamina area is the main determinant of yield loss (Waggoner \& Berger, 1987; Bryson et al., 1997; Paveley, 1999) and hence the need for fungicide treatment (Paveley et al., 2001). Here we describe a model of foliar disease progress which can be coupled with the wheat canopy model described by Milne et al. (2003) - using green canopy area as the coupling point (Boote et al., 1983) - to form part of a decision support system for fungicide treatment decisions. This use imposes certain requirements and constraints on model structure, which are considered below.

Shoemaker (1984) reviewed potential modelling approaches to determining the optimal timing of applications of pesticides and noted that simulation approaches are appropriate where, as in many agricultural systems, there are large numbers of variables. However, simulation models were considered inappropriate where there are large numbers of possible pesticide treatments and timings. This limitation can be overcome by interfacing the coupled crop-disease simulation model with a decision algorithm, such as the one described by Parsons \& Te Beest (2004). However, such an algorithm may still need to run the model thousands of times, Hence, model complexity (and therefore run time) must be minimised.

The need for fungicide treatment is commonly determined by more than one foliar disease and the progress of each disease is determined by multiple 'risk variables' (Paveley, 1999). One approach to constrain model complexity would be to use a generic model structure, which is then parameterised specifically for each of the diseases which most commonly cause substantial economic loss. In the UK, these are Septoria tritici, anamorph of Mycosphaerella graminicola (leaf blotch), Puccinia striiformis (yellow rust), Erysiphe graminis (powdery mildew) and Puccinia triticina (brown rust). The most important risk variables for each disease could then be accounted for and the diseases considered as competing for the same susceptible green canopy area.

The timing of disease development and the efficacy of fungicide treatment are both substantially determined by the emergence and expansion of successive 'layers' of culm leaves which form the upper crop canopy (Paveley et al., 2000). Hence, the model should quantify disease progress, and consequent green area loss, by leaf layer.

Fungicide active ingredients differ in their systemicity and efficacy against different stages of the pathogen life cycle. Specifically, some are only active against spores which arrive after treatment (protectant action), whereas others can prevent the expression of symptoms from latent infections (eradicant action) (Vyas, 1984). Hence, the model needs to partition pathogen growth (for instance, by date of infection), so that eradicant and protectant effects can be accounted for separately, rather than treating the epidemic as a single function (O'Callaghan et al., 1994).

When used for making tactical decisions during the growing season, user observations of disease severity can update model predictions of disease progress at key crop growth stages for fungicide treatment decisions, in order to correct for errors and omissions in the modelling. However, disease observations are subject to uncertainty (Parker et al. 1995). Hence the model should account for user observations in a way which allows for error in the observations. Kranz et al. (1984) pointed out that acceptance of models for practical use, provided they are sufficiently reliable, depends on the simplicity of input acquisition. Observations of disease need to be achievable by untrained observers and 
meteorological variables should be readily available in electronic form from synoptic stations.

Many methods have been proposed to describe, simulate or analyse botanical epidemics (for example, Jeger, 1984; Teng, 1985; Waggoner, 1986; Campbell \& Madden, 1990; Rossi et al., 1997; Yang, 1997; Segarra et al., 2001). Many of these approaches are intended to improve understanding rather than decision making. Here we describe a model designed to meet the requirements and constraints for use in farm practice to enhance decision making concerning the control of important cereal diseases.

\section{Model Structure}

Yield loss from disease is proportional to disease-induced green area loss from the upper canopy, hence the model describes disease on the top six leaves of the canopy which intercept the photosynthetically active radiation which is important for yield (Bryson et al., 1997). When describing how a single leaf layer becomes infected it is referred to here as the 'target' leaf, with leaf layers numbered downward from the flag leaf (leaf one). The processes described by the functions below are taken to apply to all the foliar diseases modelled, unless a particular disease is specified in the text. Only the most important risk variables for each disease are modelled.

\section{Disease growth on a leaf}

The simulation calculates disease progress in daily time steps. On day $t$, a number of infections occur on the leaf, which results in lesion growth. The unit of infection is the percentage of the fully developed green leaf area potentially covered by lesions. Lesion growth from an infection is modelled by a logistic function of thermal time:

$$
\frac{\mathrm{d} y}{\mathrm{~d} T}=k y(1-y) \text { with } y(0)=a,
$$

where $y$ is lesion size, expressed as a proportion of its asymptote value, at thermal time $T\left({ }^{\circ} \mathrm{C}\right.$ days, base zero). A negative base temperature has been suggested for $\mathrm{S}$. tritici (Lovell et al., 2004). At the temperature common during the life of the upper canopy the error in adopting a $0^{\circ} \mathrm{C}$ days, base temperature is relatively small. The latent period of an infection is taken as the time it takes to reach $5 \%$ of its potential size (asymptote). At this stage lesions are considered to become both infectious and visible as symptoms. Hence, lesion growth represents percentage symptom severity and the upper asymptote represents potential symptom severity. Because the asymptote value cannot be observed in practice, the maximum observed severity of disease is taken to be $90 \%$ of the asymptote value. Given these boundary conditions $k$ (rate parameter) and $a$ can be estimated from disease measurements.

Percentage symptom severity $Y(t, l)$, on leaf $l$, on day $t$, is then the sum of lesion growth from all infections which have occurred up to that point in time,

$$
Y(t, l)=\sum_{i=1}^{t} I(i, l) y(T(t)-T(i))
$$

where $I(i, l)$ is the number of successful infections occurring on day $i$ on leaf $l$, and $T(t)$ $T(i)$ is the accumulated thermal time over the period $i$ to $t$.

\section{Infection}

Until a leaf reaches $5 \%$ of its maximum area it is assumed to be enclosed in the sheath of the preceding leaf, so no infections can occur. 


\section{Inoculum source}

For the biotrophic diseases, initial infection of a crop can occur in the autumn by long distance airborne dispersal, but dispersal is more efficient over short distances. Infections develop slowly over the winter and can be subject to loss due to frosts. Hence, the level of inoculum expressed in the spring can be an important risk factor (Young et al., 2003). Inoculum generated on the lower leaves is assumed to be the predominant source of infection of the upper leaves, so the source of inoculum consists of infectious lesions in the canopy. To initiate the simulated disease growth of the $P$. striiformis, $P$. triticina and $E$. graminis, a small quantity of disease $I_{s}$ is assigned to leaf 6 , to form the spring inoculum. The value is calculated from users local observations of the previous seasons' disease severity and modified by any disease observations in the current season (see later). As infection is known to be inoculum density dependent, the relationship between potential infections $U(t, l)$ and infectious symptom area $Y(t, l)$ on leaf $l$ is

$$
U(t, l)=1-\mathrm{e}^{-a\left(Y(t, l)+Y_{s} \delta(l-6)\right)}
$$

where $\delta(l-6)$ is the Kronecker delta function which is zero except when $l=6$, when it equals one.

In the case of $S$. tritici, emerging crops become infected by long distance dispersal in the autumn and winter. Subsequently, the predominant inoculum is in the form of asexual spores produced on infectious lesions, initially on the rosette leaves (Shaw \& Royle, 1993). Sporulation can continue after leaves have senesced. Hence, the spring inoculum in the model is represented as a 'ground source' $U_{g}$, as opposed to a small level of disease on leaf 6 .

\section{Inoculum transfer}

The number of spores reaching a target leaf decreases logarithmically with distance from the inoculum source (Shaw, 1987). The distance between source and target leaf is calculated from an estimate of the height of the leaves. Leaves 5 and 6 are assumed to approximate to ground level. Leaves 1 to 4 are assumed to be at a height of $10(4-n) \mathrm{cm}$ at the point of emergence (where $n$ is the leaf number) after which they increase in height at a rate of $1 \mathrm{~cm}$ per $10{ }^{\circ} \mathrm{C}$ days until they reach a height of $10(5-n) \mathrm{cm}$.

As a simplification it is assumed that disease only spreads up the plant, because by the time an infection event on a newly emerged leaf causes infectious lesions, any spores transferred to the leaves below will have little time to express symptoms before natural senescence occurs.

The number of infections $F(t, l)$ reaching the target leaf $l$ on day $t$ is given by

$$
F(t, l)=U_{g} e^{-k h_{g}(t)}+\sum_{j=l+1}^{M} U(t, j) e^{-k h_{j}(t)}+S(t, l)
$$

where $U_{g}$ is the ground inoculum which is only non-zero for $S$. tritici, $M$ is the maximum number of diseased leaves in the model ( $\operatorname{six}), h_{j}(t)$ is the distance between leaf $l$ and leaf $j$ on day $t, h_{g}(t)$ is the distance between leaf $l$ and the ground on day $t, k$ is transfer efficiency, and $\mathrm{S}(t, l)$ is a self-infection term which describes the infections a leaf receives from its existing infectious lesions. For all diseases except $P$. triticina the self infection term is given by

$$
S(t, l)=\rho U(t, l)
$$

For $P$. triticina the self infection term is given by 


$$
S(t, l)=e^{U(t, l)}-1
$$

to reflect the rapid loss of leaf tissue once a leaf exhibits infectious lesions.

$S$. tritici spores are dispersed throughout the canopy by rain splash (Shaw \& Royal, 1993; Shaw, 1987; Schöfl, 1995). Hence the transfer efficiency $k$ in Eqn 4 is a function of rainfall

$$
k\left(r_{t}\right)=a \mathrm{e}^{-b r_{t}}
$$

where $a$ and $b$ are parameters and $r_{t}$ is the amount of rain $(\mathrm{mm})$ falling on day $t$. Daily rainfall and splash intensity are poorly correlated (Shaw, 1987), but splash intensity measurements are not widely available.

\section{Cultivar resistance}

The susceptibility of cultivars to each disease is quantified as a number from one to nine inclusive, nine being a resistant variety (Anon, 2003). The number is related to the mean percentage infection $\left(R_{C R}\right)$ recorded in recommended list trials. Successful infections are scaled as a proportion of the infection of a rating three cultivar as shown in Fig. 1 (R. Bayles, National Institute of Agricultural Botany, Cambridge, pers. comm.).

\section{Temperature}

Temperature effects on the success of infection of $P$. striiformis and $P$. triticina are modelled by the normal distribution function

$$
\begin{gathered}
R_{T}(t)=\mathrm{e}^{-\frac{(\Delta T(t)-\mu)^{2}}{2 \sigma^{2}}} \quad \text { when } \alpha<\Delta T(t)<\beta \\
\text { else } \quad R_{T}(t)=0
\end{gathered}
$$

where the thermal time $\left({ }^{\circ} \mathrm{C}\right.$ days) accumulated on day $t$ is given by $\Delta T(t)=T(t)-T(t-1)$, where $T(t)$ is the accumulated thermal time from sowing and $\mu$ and $\sigma$ are disease specific parameters. $P$. triticina has a higher optimum temperature than $P$. strifformis (De Vallavielle-Pope et al., 1995) (Fig. 2; Table 2).

Once a rust infection has established itself on the leaf and starts to grow, its growth can be terminated by frost. In the model, if the minimum temperature on a day falls below $0^{\circ} \mathrm{C}$, the growth of $10 \%$ of the infections that have occurred up until that point in time is stopped.

Temperature affects E. graminis sporulation and disease development rate. The temperature effects are modelled using a cubic equation which gives an asymmetric relationship

$$
\begin{gathered}
R_{T}=\kappa(\Delta T-\zeta)^{2}(\xi-\Delta T) \text { when } \varsigma \leq \Delta T \leq \xi \\
R_{T}=0 \quad \text { otherwise }
\end{gathered}
$$

where $\kappa, \xi$ and $\zeta$ are constant parameters. This model is based on the model given in Fredrich (1995a).

S. tritici has a wide range of temperatures over which it can develop efficiently, so temperature effects in the model were restricted to the rate of lesion growth being described in thermal time.

\section{Rain}

For $S$. tritici, the positive association between rainfall and infection is approximated by a linear relationship with a limit (Fig 2). The finding that transfer and infection can occur (by physical proximity between infectious lesions and newly emerging leaves) in 
the absence of rainfall (Lovel et al., 2004a) is represented by the intercept. However, rain can reduce the infection efficiency of some pathogens such as E. graminis by washing of spores. These effects are modelled by the function

$$
\begin{array}{rlr}
R_{\text {rain }}=\left(a+b r_{t}\right) & \frac{1-g}{1+d \mathrm{e}^{c\left(r_{t}-\Theta\right)}}+g, & r_{\mathrm{t}}<1 \\
R_{\text {rain }}=\frac{1-g}{1+d \mathrm{e}^{c\left(r_{t}-\Theta\right)}}+g, & r_{\mathrm{t}} \geq 1
\end{array}
$$

where $R_{\text {rain }}$ is effect of rain on the number of infection events, $a, b, c, d, g, \Theta$ are parameters and $r_{\mathrm{t}}$ is the rainfall $(\mathrm{mm})$ on day $t$.

The effects of rain were considered to be insufficiently well understood to parameterise for $P$. striiformis and $P$. triticina. The effects of moisture on $P$. striiformis disease risk are complex, as spores germinate poorly in free water, but require high relative humidity (De Vallavielle-Pope et al., 1995).

\section{Relative humidity}

Very high and very low relative humidities in the crop have a negative effect on $E$. graminis infection. This is modelled by the parabolic relationship

$$
\begin{array}{rrr}
R_{R H}=p H^{2}+q H-r \quad \text { when } & R_{R H} \geq 0 \\
\text { else } & R_{R H}=0
\end{array}
$$

where $\mathrm{R}_{\mathrm{RH}}$ is the effect of relative humidity on the number of infection events, $H$ is the five day moving average of relative humidity and $p, q$ and $r$ are constants.

\section{Wind speed}

With increased wind speed, the rate of E. graminis conidia liberation increases (Fredrich 1995a). The relationship used is

$$
R_{\text {wind }}=1-\mathrm{e}^{-\gamma} W(t)
$$

where $R_{\text {wind }}$ is effect of wind on the number of infection events, and $W(t)$ is the wind run $(\mathrm{km})$ on day $t$.

\section{Leaf age}

The reduction in leaf susceptibility to $P$. striiformis with age (Rapilly, 1979) is modelled by a descending sigmoidal function

$$
R_{\text {age }}=\frac{1-\alpha}{1+\beta e^{\gamma D_{t}}}+\alpha
$$

where $\alpha, \beta$ and $\gamma$ are the parameters and $\mathrm{D}_{t}$ is the leaf life $\left({ }^{\circ} \mathrm{C}\right.$ days $)$.

\section{Nitrogen}

Nitrogen $(\mathrm{N})$ increases host susceptibility to E. graminis. The relationship between susceptibility to infection $\left(R_{N}\right)$ and nitrogen uptake by the crop $(N)$ (Milne et al., 2003), is modelled by the function

$$
R_{N}=\frac{1}{1+\mathrm{e}^{-\delta N+\lambda}}
$$

\section{Number of daily successful infection events}

The number of successful infection events $I(t, l)$, occurring on leaf $l$, on day $t$ are given by the product 


$$
I(t, l)=L_{v} L_{c} R_{C R} R_{\text {Temp }} R_{\text {rain }} R_{\text {wind }} R_{R H} R_{\text {age }} R_{N} F(t, l)
$$

where $R_{C R}$ is cultivar resistance, $L_{v}(t, l)$ is the proportion of the leaf that is visible, $L_{c}(t$, $l$ ) is the proportion of undiseased leaf, and the remaining variables are defined by Eqns 5 -14 .

\section{Parameter Evaluation}

\section{Infection growth parameters}

Table 1 summarises the parameter values for each disease and the data used to derive them. The parameters of Eqn 1 are defined by the latent period and the time taken for the infection to be fully expressed. P. striiformis is recorded as having a latent period of $162^{\circ} \mathrm{C}$ days (Paveley et al., 2000). The time taken for an infection event to reach maximum size was assumed to be twice this value. $P$. triticina infections are modelled similarly. In greenhouse experiments the latent period of E. graminis lies between 55 to $75^{\circ} \mathrm{C}$ days. Under field conditions it is estimated to increase by a factor of about 1.6 (Fredrich, 1995b). Hence the latent period used here was taken to be in the mid-range of the published values at $105^{\circ} \mathrm{C}$ days.

For S. tritici the literature defines the latent period as anything from $220^{\circ} \mathrm{C}$ days to $440^{\circ} \mathrm{C}$ days (O'Callaghan et al., 1994; Royle et al., 1986; Schöfl, 1995). Schöfl's (1995) glasshouse data suggest that it is approximately $220^{\circ} \mathrm{C}$ days and a further $55^{\circ} \mathrm{C}$ days until the infection is fully developed. Field observations suggest the latent period is usually longer than this, and thus these values were scaled to $300^{\circ} \mathrm{C}$ days and $375^{\circ} \mathrm{C}$ days. These are broadly comparable with values of 250 and 301 degree days (base temp. $-2.4^{\circ} \mathrm{C}$ ) for first appearance of symptoms and time to $50 \%$ of maximal lesions, published subsequently by Lovell et al., (2004b).

\section{Infection transfer and infection efficiency parameters}

Where possible, values for the parameters were taken from the literature or fitted using experiments designed to investigate only the specific relationship. The remaining parameters were fitted to make the model simulate the levels of disease observed in field experiments. Weekly assessments of diseased area were recorded between GS 31 and maturity in untreated replicated plots of four wheat cvs. (described by Milne et al., 2003 as Data set 1). Daily weather data were collected from meteorological sites within one kilometre of the site. For each of the four diseases, the data from the most susceptible cultivar was used; Slejpner for P. striiformis, Haven and Riband for P. triticina, Apollo for E. graminis and Riband for $S$. tritici.

A small number of data were not used where observation or transcription errors resulted in illogical disease progress curves. The model was run with each weather file in succession, with the appropriate sowing dates, latitude, and soil nitrogen levels. The canopy simulation was corrected, where necessary, so that the leaves emerged and senesced at the times noted in the trial. Simulated disease levels occurring at times corresponding to those observed were output from the model run. A non-linear optimisation scheme was used to find the parameter values that would minimise the difference between simulated and observed disease levels on the top four leaves over the whole data set. The code that carries out this minimisation was taken from the IMSL Fortran library. It used a modified Levenberg-Marquart method and an active strategy to solve the nonlinear least squares problem (Gill et al., 1981).

Non-linear optimisation algorithms often only find a local minimum of a complex 
system, not the global minimum. Hence, care was taken to choose suitable initial conditions and parameter bounds, by ensuring that the biological interpretation of the functions was sound and investigating the effects of the parameters on the disease progression.

To take account of sensitivity to initial inoculum, in the cases of $P$. striiformis, $P$. triticina, and E. graminis, initially the data sets were sorted into high and low disease pressure sites. The unassigned parameters, which in each case included $Y_{\mathrm{s}}$, were fitted to the high disease pressure data sets, after which a second value for $Y_{\mathrm{s}}$ was then calculated using the low disease pressure sets.

The results of the parameter evaluation are shown in Table 2, where in each case the source of each parameter value is indicated. Fig. 2 shows the model components plotted using the parameters given in the table. Fig. 3 illustrates the disease progress curve for Septoria leaf blotch plotted against some data from the experiments described above, showing how the model accurately simulates the interruption in disease development caused by a period of dry weather.

\section{Observations during the growing season}

Observations can be used to modify the simulations in two ways. Firstly, initial inoculum levels, or in the case of $S$. tritici ground inoculum, can be adjusted so that the simulation reflects the user observations. A mechanism was incorporated to allow for the emergence of new virulent pathotypes (for example, of $P$. striiformis) which cause previously resistant cultivars to become susceptible. If adjusting inoculum levels fails to compensate sufficiently for the discrepancies between the model and simulation, the level of cultivar resistance is assumed to have fallen. In such cases the cultivar susceptibility is adjusted until the simulated values of the disease fall within predetermined limits of the observation.

Diseases can be assessed as more serious than they actually are, or underestimated, or the foci of disease can be missed despite being present (Parker et al. 1995). Hence, observation handling procedures were developed that incorporate a prior knowledge of disease risk with the observation.

\section{Adjusting inoculum levels for biotroph models}

The inoculum levels are estimated by taking into account previous levels of disease at a site, and observations of disease in the current season. For E. graminis, P. striiformis and $P$. triticina this was done using Bayes' theorem (DeGroot, 1989).

A site is defined as being at very high $(\mathrm{VH})$, high $(\mathrm{H})$, medium $(\mathrm{M})$, or low (L) risk of disease, which reflects the number of previous years with very high, high and medium levels of disease. The user chooses the site type based on a set of definitions. A specific year will have an unknown $\mathrm{VH}, \mathrm{H}, \mathrm{M}$, or L level of disease. Thus, a site that is considered to be at medium risk can, for example, have a very high disease year. The probability of a level of observation for each type of year can be determined from experimental data. Thus using Bayes' theorem, the probability that a year is a certain type given a disease observation can be calculated. In terms of this application, Bayes' theorem states

$$
\text { Prob(Year|Obs)=Prob(Obs|Year) Prob(Year)/Prob(Obs), }
$$

where | means "given". The observation (Obs) is also classified as being a $\mathrm{VH}, \mathrm{H}, \mathrm{M}$ or L type but may be an incorrect estimate of the specific year. 
Using expert opinion and data from the trials described above, the prior probabilities of the year types occurring at given site types were derived. The values for $P$. striiformis are shown in Table 3. The probabilities of an observation occurring in the different year types were determined. It is more likely not to observe disease when it does exist than to observe it when it doesn't exist. For P. striiformis, these values are shown in Table 4. Each type of year has an associated initial inoculum level. Using weather from the current year, the model simulates the expected observation for each year type. Using this information, the actual observation is classified as being a $\mathrm{VH}, \mathrm{H}$, $\mathrm{M}$ or L type and thus modifies the prior probabilities of the type of disease year.

The information needed to calculate the probability of a certain year type occurring given a particular observation can be found in the Tables 3 and 4. For example, at a VH site, given a $\mathrm{VH}$ observation, the probability of the year being high risk is given by

Prob(VHyear|VHObs) = Prob(VHObs|VHyear) Prob(VHYear) / Prob(VHObs) (17)

In the $P$. striiformis example, the probability of a $\mathrm{VH}$ observation given a $\mathrm{VH}$ year is 0.4 . The probability of a $\mathrm{VH}$ year at this very high site is 0.8 . The probability of a VH observation is given by the sum of the probability of a $\mathrm{VH}$ observation at a given year type (Table 4) multiplied by the probability of the given year type at the VH site (Table 3 ), which in this example is 0.34 . Therefore the Prob(VHyear|VHObs) $=0.941$. Similar calculations show that this very high observation revises the probability of $\mathrm{VH}, \mathrm{H}, \mathrm{M}, \mathrm{L}$ year types from $(0.8,0.2,0.0,0.0)$ to $(0.941,0.059,0.0,0.0)$.

For $P$. striiformis, $P$. triticina and E. graminis the levels of risk are incorporated into the model by the inoculum parameter $I_{\mathrm{s}}=b \times 10^{-a}$, where $b$ is a constant parameter and $a$ is assigned a value depending on disease risk. In the case of $P$. striiformis $b=5$ and the exponent $a$ is set to 2.0, 3.0, 4.4, 6.5 for $\mathrm{VH}, \mathrm{H}, \mathrm{M}, \mathrm{L}$ respectively. The probabilities of each of the levels of risk occurring are applied to the exponent values to give a new value based on user observation and site type. In the example described above, the new exponent value is given by $2.0 \times 0.941+3.0 \times 0.059=2.059$. If no observation had been made the exponent would be $2.0 \times 0.8+3.0 \times 0.2=2.2$, which would give slightly lower levels of disease. The list of possible new values for the exponent is given in Table 5

\section{Adjusting ground disease levels for $\mathrm{S}$. tritici model}

The model considers disease progress from leaf six onward and any previous climatic effects on disease (Gladders et al., 2001) are only accounted for through subsequent disease observations. Disease levels can be quite varied early in the season, so a facility to adjust ground disease was needed. The methodology was similar to the one used for the other diseases. However, the effects of observations of disease at low severities were reduced to avoid very small changes in observations resulting in excessive effects on predictions. The year can be very high $(\mathrm{VH})$, high $(\mathrm{H})$, medium $(\mathrm{M})$, low $(\mathrm{L})$, or very low (VL) (initially the default is the mid-point, as no initial perception of site type is available). The beta distribution was used to calculate the probability of being in a particular year type, given an observation, as it gives the desired behaviour. The beta distribution was defined as $\beta(y: a, b)$, where $0.0<y \leq 0.2$ for VL, $0.2<y \leq 0.4$ for L, $0.4<y \leq 0.6$ for $\mathrm{M}, 0.6<y \leq 0.8$ for $\mathrm{H}, 0.8<y \leq 1.0$ for $\mathrm{VH}$. The parameters are defined as $a=1+$ (observed disease) $/ 7.0$ and $b=1+($ simulated disease with moderate inoculum)/7.0. Fig. 4 shows the distribution with four different combinations of observed and simulated disease level.

The ground inoculum was of the form $U_{g}=3.25 \times 10^{a}$, where the exponent $a$ is the parameter adjusted by disease observations. The values of $a$ for VL, L, M, H, VH are - 
$1,0,1,2,3$ respectively. If an observation was made, then the value of the parameter $a$ was altered to the probability weighted average:

$$
a=-\operatorname{Prob}(\mathrm{VL} / \mathrm{Obs})+\operatorname{Prob}(\mathrm{M} / \mathrm{Obs})+2 \operatorname{Prob}(\mathrm{H} / \mathrm{Obs})+3 \text { Prob }(\mathrm{VH} / \mathrm{Obs})
$$

\section{Model Validation}

\section{Materials and methods}

In the 1999/2000 season, randomised and replicated field plots of winter wheat were established at eight sites across the UK, selected to represent a wide range of environments and disease pressure. Two cvs were grown at Aberdeen, Aberdeenshire (cvs Abbot and Claire), High Mowthorpe, North Yorkshire (Abbot and Consort), Morley, Norfolk (Abbot and Consort), Rosemaund, Herefordshire (Abbot and Consort), and Starcross, Devon (Abbot and Buster), three at Terrington, Norfolk (Abbot, Brigadier and Harrier), and one each at Limavady, N. Ireland (Abbot) and Moira, N. Ireland (Consort). Plots received no fungicide treatments. Nitrogen fertilizer was managed to achieve a canopy size of approximately GAI six. Leaf emergence dates and percentage disease were recorded weekly for each leaf layer that had emerged (ligule visible), on ten randomly sampled shoots from each of the three replicate plots of each cultivar.

The disease simulation was run for each site using weather data collected from that site, along with information on sowing date and longitude.

\section{Results}

Tables $6 \mathrm{a}$ and $6 \mathrm{~b}$ compare simulated and observed disease severity on the top two leaves. The last four weekly observations on each leaf were used. The first number in each category set shows the number of simulation/observation sets that fall in the category without using a disease observation, and the number in brackets is the amount after a single disease observation correction around GS37 was used. Where possible the first observation of disease on leaf 4 was used. In cases where this was not available an observation on a higher leaf was used. Categories of disease severity were chosen to reflect the non-linear relationship between disease and the appropriate fungicide dose. Severities above $20 \%$ were not subdivided, as such large values usually lead to a dose close to, or at, the maximum being applied. Simulated and observed disease severities for $P$. triticinia and E. graminis all fell in the lowest two categories, so figures have not been produced. The $S$. tritici tables show comparisons of the disease growing on the cvs Abbot, Consort, Claire, Buster, Brigadier and Harrier. The P. striiformis tables show comparisons of the disease growing on the cvs Abbot, Brigadier and Harrier. In these simulations $P$. striiformis inoculum was set to 'High' for sites on the east coast, which in the past had severe cases of $P$. striiformis, and 'Low' for others.

The results of the simulation showed that the model responded correctly, across the eight contrasting validation sites, to a different season and different varieties than those used for parameter estimation. For $S$. tritici, simulated severity values were within one category of the observed values for $88 \%$ and $81 \%$ of cases, with and without an update to the simulation, respectively (Table 6a). The equivalent values for yellow rust were $91 \%$ and $85 \%$ (Table 6b). For both diseases, in the relatively small number of cases where prediction was imprecise, predicted severities were greater than observed.

\section{Discussion}


The model provided predictions of the development of the four foliar diseases on each of the upper culm leaves of wheat that are most important in determining the impact of disease on grain yield. Here, we consider the extent to which each of the model requirements, described in the introduction, were met.

The model has been implemented as part of a decision support system (Parsons et al., 2004), by coupling with canopy (Milne et al., 2003), fungicide application, yield loss and decision models (Parsons \& Te Beest, 2004). Hence, the run time has been quantified in practice. Selecting a list of appropriate fungicide programmes (fungicide products, dose and timings within the next four week period), ranked by margin over treatment cost, typically takes 20 seconds using an $1.8 \mathrm{Ghz}$ computer. During this optimization process, the process model is run approximately 2000 times.

The requirement for simplicity constrained the number of risk variables that were accounted for with each disease. It is not feasible to quantify the relative importance of a wide range of risk variables simultaneously in an experiment. Hence, the choice of which variables to include or exclude is somewhat subjective, although analysis of survey data can provide a guide (Gladder et al., 2001) and validation can provide a measure of the resulting predictive value. With a single disease observation in midseason to update the simulation, predicted disease severity values were acceptably close to observed values in approximately $90 \%$ of cases. In the remaining cases, disease was over-predicted. Such errors are of less concern than erroneous false negatives, as they are risk-averse.

The models for the four diseases were considered as competing for the same green lamina area. However, the level of disease control required in commercial practice means that all diseases are constrained to low severities and competition for green area is of less consequence than for untreated crops. As there might be a small competitive advantage to the disease which is called first, in each time step of the algorithm, the effect of changing the order was tested and was found to be trivial. However, it was found that if the simulation was run with a cultivar that was susceptible to both $P$. striiformis and $S$. tritici at a site designated as high or very high risk to $P$. striiformis, then (in the absence of fungicide treatment or user observations) levels of $P$. striiformis on the lower leaves were lower than observed in the data and the levels of $S$. tritici were higher. This phenomenon decreased up the canopy until on the flag leaf, simulated disease severity agreed with that observed. The latent period for P. striiformis is shorter than that for $S$. tritici, hence the former can out-compete the latter. But in the model the $S$. tritici ground inoculum put $P$. striiformis at an initial competitive disadvantage. Although these effects were not particularly important once fungicide applications were made, they were affecting the predictions of disease-induced yield loss. To overcome this, the $S$. tritici ground inoculum was reduced when the cultivar is susceptible to $P$. striiformis (cultivar resistance $<4$ ) and the site is designated as high or very high risk to P. striiformis.

Mechanisms were implemented to allow observations of disease to be used to update the predictions of disease progress during the growing season. A single observation at a key growth stage for fungicide treatments (flag leaf emergence) was sufficient to improve the prediction of severity on the upper leaves during grain filling. Without observations, predictions were risk averse. In practice, two or three observations at key growth stages would not make excessive time demands of users.

\section{Acknowledgements}


Funding from Department for Environment Food and Rural Affairs and the HomeGrown Cereals Authority is gratefully acknowledged. We would also like to thank Steve Parker, Kris Jewell and Paul Maddaford for their contributions to this work.

\section{References}

Anon. 2003. HGCA Recommended List 2003/04 for cereals and oilseeds. HomeGrown Cereals Authority, London, UK.

Boote K J, Jones J W, Mishoe J W, Berger R D. 1983. Coupling pests to crop growth simulators to predict yield reductions. Phytopathology 73:1581-1587.

Bryson R J, Paveley N D, Clark W S, Sylvester-Bradley R, Scott R K. 1997. Use of in-field measurements of green leaf area and incident radiation to estimate the effects of yellow rust epidemics on the yield of winter wheat. European Journal of Agronomy 7:53-62.

Campbell C L, Madden L V. 1990. Temporal analysis of epidemics I: description and comparison of disease progress curves. In Introduction to Plant disease epidemiology, pp. 161-202. New York: Wiley.

DeGroot M H. 1989. Probability and Statistics, second edition. Massachusetts: Addison Wesley.

Fredrich S. 1995a. Calculation of conidial dispersal of Erysiphie graminis within naturally infected plant canopies using hourly meterological input parameters. Journal of Plant Diseases and Protection 102:337-347.

Fredrich S. 1995b. Calculation of the incubation period of powdery mildew under field conditions. Journal of Plant Diseases and Protection 102:348-353.

Fredrich S. 1995c. Modelling infection probability of powdery mildew in winter wheat by meteorological input variables. Journal of Plant Diseases and Protection 102:354365.

Gill P E, Murray W, Wright M. 1981. Practical Optimisation. New York: Academic Press.

Gladders P, Paveley N D, Barrie I A, Hardwick N V, Hims M J, Langton S, Taylor MC. 2001. Agronomic and meteorological factors affecting the severity of leaf blotch caused by Mycosphaerella graminicola in commercial wheat crops in England. Annals of Applied Biology 138:301-311.

Jeger M J. 1984. The use of mathematical models in plant disease epidemiology. Scientific horticulture 35:11-27.

Kranz J, Hau B, Aust H J. 1984. Monitoring in crop protection modeling. In Pest and pathogen control: strategic, tactical and policy models, pp. 233-241. Ed. G R Conway. Wiley.

Lovell D J, Parker, S R, Hunter T, Welham S J, Nicholls A R. 2004a. Position of inoculum in the canopy affects the risk of Septoria tritici blotch epidemics in winter wheat. Plant pathology 53:11-21.

Lovell D J, Hunter T, Powers S J, Parker S R, Van den Bosch F. 2004b. Effect of temperature on latent period of septoria leaf blotch on winter wheat under outdoor conditions. Plant Pathology 53:170-181.

Milne A, Paveley N, Audsley E, Livermore P. 2003. A wheat canopy model for use in disease management decision support systems. Annals of Applied Biology 143:265274. 
O'Callaghan J R, Dahab M H, Hossain A H M S, Wyseure G C L. 1994. Simulation of Septoria tritici- winter wheat interactions. Computers and Electronics in Agriculture 11:309-321.

Parker S R, Shaw M W, Royle D J. 1995. The reliability of visual estimates of disease severity on cereal leaves. Plant Pathology 44:856-864.

Parsons D J, Te Beest D. 2004. Optimising fungicide applications on winter wheat using genetic algorithms. Biosystems Engineering 88:401-410.

Parsons D J, Mayes J A, Meakin P, Offer A, Paveley ND. 2004. Taking DESSAC forward with the Arable Decision Support Community. Advances in applied biology: providing new opportunities for consumers and producers in the $21^{\text {st }}$ century, Oxford UK.

Paveley N D. 1999. Integrating septoria risk variable. In Septoria on cereals: a study of pathosystems, pp 230-250. Oxfordshire: CABI.

Paveley N D, Lockley D, Vaughan T B, Thomas J, Schmidt K. 2000. Predicting effective fungicide dose through observation of leaf emergence. Plant Pathology 49:748-766.

Paveley N D. Sylvester-Bradley R, Scott R K, Craigon J, Day W. 2001. Steps in predicting the relationship of yield on fungicide dose. Phytopathology 91:708-716.

Rapilly F. 1979. Yellow rust epidemiology. Annual Reviews of Phytopathology 17:5973.

Rossi V, Racca P, Giosue S, Pancaldi D, Alberti I. 1997. A simulation model for the development of brown rust epidemics in winter wheat. European Journal of Plant Pathology 103:453-465.

Royle D J, Shaw M W, Cook R J. 1986. Patterns of development of Septoria nodorum and Septoria tritici in some winter wheat crops in Western Europe, 1981-1983. Plant Pathology 35:466-476.

Schöfl U. 1995. Evaluation of decision support systems to control foliar diseases on wheat in the UK, with additional specific studies on septoria tritici. $\mathrm{PhD}$ Thesis from Lehrstuhl für Phytopathologie Technische Universität München, Germany.

Segarra J, Jeger M J, van den Bosch F. 2001. Epidemic dynamics and patterns of plant diseases. Phytopathology 91:1001-1010.

Shaw M W. 1987. Assessment of upward movement of rain splash using a florescent tracer method and its application to the epidemiology of cereal pathogens. Plant Pathology 36:201-213.

Shaw M W, Royle D J. 1993. Factors determining the severity of epidemics of Mycosphaerella graminicola (Septoria tritici) on winter wheat in the UK. Plant Pathology 42:882-899.

Shoemaker C A. 1984. The optimal timing of multiple applications of residual pesticides: deterministic and stochastic analyses. In Pest and pathogen control: strategic, tactical and policy models, pp. 290-309. Ed. G R Conway. Wiley.

Teng P S. 1985. A comparison of simulation approaches to epidemic modelling. Annual Review of Phytopathology 23:351-379.

De Vallavielle-Pope C, Hube L, Leconte M, Goyeau H. 1995. Comparative effects of temperature and interrupted wet periods on germination, penetration, and infection. Ecology and Epidemiology 85:409-415.

Vyas S A. 1984. Systemic fungicides. New Delhi: Tata McGraw Hill.

Waggoner P E. 1986. Progress curves of foliar diseases: their interpretation and use. In Plant disease epidemiology; population dynamics and management, 1, pp. 3-37. Eds. 
K J Leonard and W E Fry. Macmillan

Waggoner P E, Berger R D. 1987. Defoliation, disease, and growth. Phytopathology 77:393-398.

Yang X B. 1997. Modeling plant disease dynamics using neural networks. AI Applications 11:47-55.

Young C S, Paveley N D, Vaughan T B, Thomas J M, Lockley K D. 2003. Predicting epidemics of yellow rust (Puccinia striiformis) on the upper canopy of wheat from disease observations on lower leaves. Plant Pathology 52:338-349. 
Table 1. Parameter values for the unit infection growth Eqn 1, for P. striiformis, P. triticina, E. graminis and S. tritici, and thermal time data used to evaluate them

\begin{tabular}{lcccc}
\hline & $P$. striiformis & P. triticina & E. graminis & S.tritici \\
\hline $\begin{array}{l}{ }^{\circ} \mathrm{C} \text { days to 5\% } \\
\text { disease expressed }\end{array}$ & 162 & 162 & 105 & 300 \\
${ }^{\circ} \mathrm{C}$ days to 90\% & 324 & 324 & 234 & 375 \\
disease expressed & & & & \\
$k$ & 0.032 & 0.032 & 0.04 & 0.079 \\
$a$ & 7.88 & 7.88 & 7.15 & 26.5 \\
\hline
\end{tabular}


Table 2. Model parameter values and the source of their derivation

\begin{tabular}{|c|c|c|c|c|c|c|c|c|c|}
\hline \multicolumn{2}{|c|}{ Eqn } & \multicolumn{2}{|c|}{ P. striiformis } & \multicolumn{2}{|c|}{ P. triticina } & \multicolumn{2}{|c|}{ E. graminis } & \multicolumn{2}{|c|}{ S.tritici } \\
\hline \multirow[t]{2}{*}{3} & $\mathrm{Y}_{\mathrm{s}}$ & 0.005 & $\mathrm{a}$ & 0.01 & $\mathrm{a}$ & 0.1 & $\mathrm{a}$ & 0.0 & \\
\hline & $a$ & 2.0 & $\mathrm{~b}$ & 2.0 & $\mathrm{~b}$ & 2.0 & $\mathrm{~b}$ & 2.0 & $\mathrm{~b}$ \\
\hline \multirow[t]{2}{*}{4} & $k$ & 0.01 & $\mathrm{~b}$ & 0.16 & $\mathrm{~b}$ & & & - & $\mathrm{c}$ \\
\hline & $\mathrm{U}_{\mathrm{g}}$ & 0.0 & & 0.0 & & 0.0 & & 3.25 & $\mathrm{~b}$ \\
\hline 5 & $\Delta$ & 1.0 & $\mathrm{~b}$ & 0 & d & 1.1 & $\mathrm{~b}$ & 1.8 & $\mathrm{~b}$ \\
\hline \multirow[t]{2}{*}{7} & $a$ & & & & & & & 0.16 & $\mathrm{e}$ \\
\hline & $b$ & & & & & & & 0.28 & $\mathrm{~b}$ \\
\hline \multirow[t]{4}{*}{8} & : & 11.0 & $\mathrm{f}$ & 17.0 & $\mathrm{~g}$ & & & & \\
\hline & $\Phi$ & 3.5 & & 4.0 & & & & & \\
\hline & $\forall$ & 0.0 & & 0.0 & & & & & \\
\hline & $\exists$ & 30.0 & & 30.0 & & & & & \\
\hline \multirow[t]{3}{*}{9} & 6 & & & & & 0.0005 & $\mathrm{~h}$ & & \\
\hline & . & & & & & 2.0 & & & \\
\hline & $>$ & & & & & 25.0 & & & \\
\hline \multirow[t]{6}{*}{10} & $a$ & & & & & 0.75 & $\mathrm{~b}$ & 0.1 & $\mathrm{~b}$ \\
\hline & $b$ & & & & & 0.05 & & 0.1 & \\
\hline & $c$ & & & & & 2.0 & & - & \\
\hline & $d$ & & & & & 0.001 & & 0.0 & \\
\hline & $g$ & & & & & 0.1 & & 0.0 & \\
\hline & $\Theta$ & & & & & 5.0 & & 9.0 & \\
\hline \multirow[t]{3}{*}{11} & $p$ & & & & & -0.01 & $\mathrm{~b}$ & & \\
\hline & $q$ & & & & & 1.2 & & & \\
\hline & $r$ & & & & & -35.0 & & & \\
\hline 12 & ( & & & & & 0.005 & $\mathrm{i}$ & & \\
\hline \multirow[t]{3}{*}{13} & $\forall$ & 0.1 & $\mathrm{~b}$ & & & 0.7 & $\mathrm{~b}$ & & \\
\hline & $\exists$ & 0.001 & & & & 0.001 & & & \\
\hline & ( & 0.02 & & & & 0.2 & & & \\
\hline \multirow[t]{2}{*}{14} & * & & & & & 0.1 & $\mathrm{~b}$ & & \\
\hline & 8 & & & & & 6.0 & & 0 & \\
\hline
\end{tabular}

a derived from data from high inoculum sites from experimental data (Paveley unpublished, see text)

b derived from experimental data (Paveley unpublished, see text)

c see Egn 7

d see Egn 12

e S Parker (Pers. comm.)

f Rapilly (1979); De Vallavielle - Pope et al. (1995)

g De Vallavielle - Pope et al. (1995)

h based on Fredrich (1995b)

i based on Fredrich (1995a) 
Table 3. At a site of one risk type, the probability of a year of each disease severity type occurring for $\mathrm{P}$. striiformis. $\mathrm{VH}$ - very high; $\mathrm{H}$ - high, $\mathrm{M}$ - medium; L - low

Year type

\begin{tabular}{ccccc}
\hline Site type & VH & H & M & L \\
VH & 0.8 & 0.2 & 0 & 0 \\
H & 0.2 & 0.6 & 0.2 & 0 \\
M & 0.1 & 0.3 & 0.4 & 0.2 \\
L & 0 & 0.1 & 0.3 & 0.6 \\
\hline
\end{tabular}


Table 4. Given a particular type of year, the probability of a $\mathrm{P}$. striiformis observation being that associated with another type of year

\begin{tabular}{ccccc}
\hline & \multicolumn{5}{c}{ Observation type } \\
\hline Year type & $\mathrm{L}$ & $\mathrm{M}$ & $\mathrm{H}$ & $\mathrm{VH}$ \\
$\mathrm{VH}$ & 0.1 & 0.2 & 0.3 & 0.4 \\
$\mathrm{H}$ & 0.2 & 0.3 & 0.4 & 0.1 \\
$\mathrm{M}$ & 0.4 & 0.5 & 0.1 & 0 \\
$\mathrm{~L}$ & 0.8 & 0.2 & 0 & 0 \\
\hline
\end{tabular}


Table 5. Exponent values for $\mathrm{P}$. striiformis observations made at different site types

\begin{tabular}{cccccc}
\hline \multicolumn{5}{c}{ Observation } \\
\hline Site type & None & VH & H & M & L \\
VH & 2.2 & 2.06 & 2.25 & 2.27 & 233 \\
H & 3.08 & 2.43 & 2.9 & 3.32 & 3.32 \\
M & 4.16 & 2.43 & 2.82 & 4.13 & 4.94 \\
L & 5.52 & 3 & 3.6 & 5.06 & 5.9 \\
\hline
\end{tabular}


Table 6a. Comparisons between simulated S.tritici $(s)$ and the observed disease $(d)$ on the cvs Abbot, Consort, Claire, Buster, Brigadier and Harrier in field validation trials. The numbers show observations/simulated values that fall into each category. Numbers in brackets show the number of values that fall into each category after an observation made on leaf 4 at GS 37 was used to update the simulation part way through the season.

Leaf 1

\begin{tabular}{|c|c|c|c|c|c|}
\hline \% disease & $0 \# s \# 1$ & $1<s \# 5$ & $5<s \# 10$ & $10<s \# 20$ & $20<s$ \\
\hline 0\# d \#1 & $\begin{array}{ll}7 & \\
& (12)\end{array}$ & $\begin{array}{ll} & \\
& (5)\end{array}$ & $\begin{array}{ll}8 & \\
& (6)\end{array}$ & 1 & \\
\hline $1<d \# 5$ & ${ }^{2}$ (2) & $\begin{array}{l}5 \\
(5)\end{array}$ & 4 & $\begin{array}{l}4 \\
\text { (3) }\end{array}$ & \\
\hline $5<d \# 10$ & & & ${ }^{4}$ & $\begin{array}{l}2 \\
\end{array}$ & 2 \\
\hline $10<d \# 20$ & & & 1 & $\begin{array}{ll}5 & \\
& (6)\end{array}$ & 1 \\
\hline $20<d$ & & & & $\begin{array}{ll}5 & \\
& (4)\end{array}$ & 2 \\
\hline
\end{tabular}

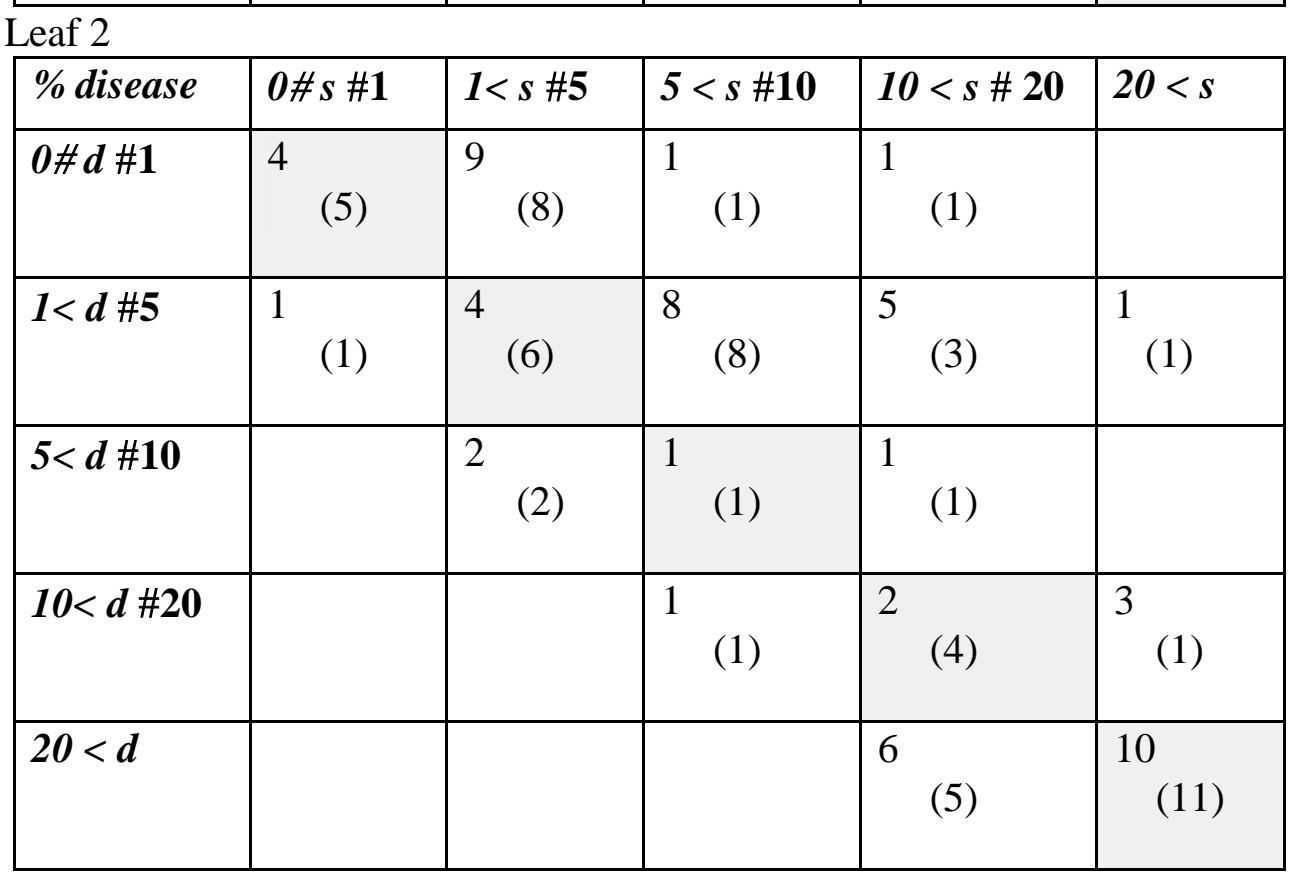


Table 6b Comparisons between simulated $P$. striiformis $(s)$ and the observed disease $(d)$ on the cvs Abbot, Brigadier and Harrier in field validation trials.

\begin{tabular}{|c|c|c|c|c|c|}
\hline \% disease & $0 \# s$ \#2 & $2<s \# 10$ & $10<s \# 20$ & $20<s \# 35$ & $35<s$ \\
\hline $0 \# d \# 2$ & $\begin{array}{ll}8 & \\
& (8)\end{array}$ & $\begin{array}{ll} & \\
& \end{array}$ & $\begin{array}{l}2 \\
(2)\end{array}$ & & \\
\hline $2<d \# 10$ & & $\begin{array}{l}2 \\
(2)\end{array}$ & $\begin{array}{ll}1 \\
\end{array}$ & & \\
\hline $10<d \# 20$ & & 1 & $\begin{array}{ll}2 \\
\end{array}$ & $\begin{array}{ll}2 & \\
& (2)\end{array}$ & $\begin{array}{ll}1 & \\
& (1)\end{array}$ \\
\hline $20<d \# 35$ & & & 1 & (1) & \\
\hline $35<d$ & & & 1 & $\begin{array}{ll}1 & \\
& (2)\end{array}$ & $\begin{array}{l}3 \\
\text { (3) }\end{array}$ \\
\hline
\end{tabular}

\begin{tabular}{|c|c|c|c|c|c|}
\hline & & & & & \\
\hline \% disease & $0 \# s \# 2$ & $2<s \# 10$ & $10<s \# 20$ & $20<s \# 35$ & $35<s$ \\
\hline $0 \# d \# 2$ & $\begin{array}{ll}9 & \\
& (9)\end{array}$ & $\begin{array}{ll}1 & \\
& (1)\end{array}$ & $\begin{array}{ll}1 & \\
& \text { (1) }\end{array}$ & & \\
\hline $2<d \# 10$ & & & $\begin{array}{ll}2 & \\
& \end{array}$ & & \\
\hline $10<d \# 20$ & & $\begin{array}{ll}4 \\
\end{array}$ & $\begin{array}{ll}5 & \\
& (7)\end{array}$ & & \\
\hline $20<d \# 35$ & & $\begin{array}{ll} & \\
& (1)\end{array}$ & (1) & $\begin{array}{ll}1 & \\
& (1)\end{array}$ & \\
\hline $35<d$ & & 1 & & (1) & $\begin{array}{ll}2 & \\
& \end{array}$ \\
\hline
\end{tabular}




\section{Figure Legends}

Fig. 1. The effect of cultivar resistance on infection.

Fig 2. The model scaling factors for the effects of risk variables on epidemic progress for each disease. (excludes plots of relative humidity, wind run and nitrogen on mildew)

Fig 3. Illustration of simulated (-) and measured (-) disease progress curves $\%$, for Septoria leaf blotch (Paveley, unpublished data) measured on cv. Riband. An observation of leaf 3 emergence was used to ensure the simulated canopy emergence was similar to the observed.

Fig 4. The probability distribution function for being in very high, high, moderate, low and very low risk S.tritici years given (a) a low $(0.5 \%)$ observation and a low $(0.5 \%)$ simulated disease value, (b) a low (0.5\%) observation and a high (10\%) simulated disease value, (c) a high (10\%) observation and a low (0.5\%) simulated disease value, (d) a high (10\%) observation and a high (10\%) simulated disease value. 
t day number

Glossary of variables

1 leaf number

$D_{t} \quad$ leaf life ( ${ }^{\circ} \mathrm{C}$ days)

$F(t, l) \quad$ number of infections reaching leaf 1 on day $\mathrm{t}$

$H$ the five day moving average of relative humidity, \%

$h_{j}(t) \quad$ the distance between the target leaf and leaf $j$ (g=ground) on day $t, \mathrm{~cm}$

$I(\mathrm{t}, l)$ the number of successful infections occurring on day $i$ on leaf $l$

$k\left(r_{t}\right) \quad$ transfer efficiency of disease between leaves (function of rain)

$L_{v}(t, l)$ the proportion of the leaf that is: $\mathrm{v}=$ visible, $\mathrm{c}=$ undiseased

$M \quad$ maximum number of diseased leaves in the model (six)

$\mathrm{N} \quad$ nitrogen uptake by the crop, $\mathrm{kgN} / \mathrm{ha}$

$R_{X} \quad$ factors for the effect of: $\mathrm{CR}=$ cultivar resistance, $\mathrm{T}=$ temperature, rain=rain, $\mathrm{RH}=$ relative humidity, $\mathrm{N}=$ nitrogen

$r_{t} \quad$ the amount of rain ( $\mathrm{mm}$ ) falling on day $t$

$\mathrm{S}(t, l)$ infections a leaf receives from its own existing infectious lesions.

$\mathrm{T}(\mathrm{t}) \quad$ accumulated thermal time on day $\mathrm{t}\left({ }^{\circ} \mathrm{C}\right.$ days, base zero)

$\Delta T(t) \quad=T(t)-T(t-1)$

$U(t, l)$ potential infections from leaf 1 on day $\mathrm{t}$

$U_{g} \quad$ the ground inoculum which is only non-zero for $S$. tritici

$Y(t, l) \quad$ symptom severity expressed as a proportion of its asymptote value

$\mathrm{Y}_{\mathrm{s}} \quad$ background symptom severity

$\delta(\mathrm{v}) \quad$ Kronecker delta function: $=1$ if $\mathrm{v}=0$, else zero

All other symbols are parameters defined in Table 2. 